\title{
PRODUÇÃO DE BIOSSURFACTANTE POR BACILLUS SUBTILIS UTILIZANDO RESÍDUO DO PROCESSAMENTO DO ABACAXI COMO SUBSTRATO
}

\author{
D. D. Ehrhardt ${ }^{1}$, J.F.F. Secato ${ }^{1}$ e E. B. Tambourgi ${ }^{1}$ \\ ${ }^{1}$ Universidade Estadual de Campinas - Departamento de Engenharia Química
}

\begin{abstract}
RESUMO - Biossurfactantes são grupos de compostos químicos produzidos por bactérias, fungos e leveduras através da biodegradação de matériasprimas renováveis. Tais compostos possuem característica anfipática, agindo como emulsificantes de hidrocarbonetos. São polímeros que formam micelas que se acumulam na interface entre líquidos de diferentes graus de polaridade. A demanda por surfactantes aumentou consideravelmente dentro da indústria química. A utilização de biossurfactantes tornou-se uma alternativa bastante interessante em substituição aos surfactantes sintéticos, pois geram menor impacto ambiental devido à sua biodegrabilidade, diversidade estrutural e baixa toxicidade. O presente trabalho teve como objetivo a produção de biossurfactante através da fermentação do resíduo do processamento do abacaxi, por Bacillus subtilis, a $37{ }^{\circ} \mathrm{C}$. Os resultados mostraram que houve uma redução de $20 \%$ da tensão superficial nos testes preliminares e uma redução de $16 \%$ nas condições do planejamento, $\mathrm{pH} 8 \mathrm{e}$ $20 \%$ inóculo. Os índices de emulsificação atingiram valores de 53\% tanto para o óleo de soja como para o óleo de motor.
\end{abstract}

\section{INTRODUÇÃO}

Os surfactantes fazem parte de uma importante classe de produtos químicos amplamente utilizados em diversos ramos industriais. São moléculas anfipáticas, constituídas por uma porção hidrofóbica e outra hidrofílica, onde a porção apolar é, frequentemente, uma cadeia hidrocarbonada, enquanto a porção polar pode ser iônica, não-iônica ou anfotérica. Essa característica anfifílica permite que tais substâncias possuam grande ação superficial.

Biossurfactantes são grupos de compostos químicos produzidos por bactérias, fungos ou leveduras, que também possuem característica anfipática, agindo como emulsificadores de hidrocarbonetos. Assim como os surfactantes, são polímeros que 
formam micelas que se acumulam na interface entre líquidos de diferentes graus de polaridade.

Nas últimas décadas a demanda por surfactantes aumentou cerca de $300 \%$ dentro da indústria química americana. A utilização de biossurfactantes, tensoativos de origem microbiana, tornou-se uma alternativa bastante viável, em comparação aos surfactantes sintéticos.

Os biossurfactantes ganharam maior atenção por apresentarem algumas vantagens em relação aos surfactantes, tais como: biodegrabilidade, baixa toxicidade, aceitabilidade ecológica e possibilidade de serem produzidos com a utilização de matérias-primas renováveis, de baixo custo (Nitschke e Pastore, 2006). A vasta aplicação destes compostos e suas propriedades são muito interessantes. Dentre eles podemos citar os lipopeptídeos, usualmente produzidos por Bacillus (Ghodjavand et al., 2008).

Os biossurfactantes, de modo geral, podem ser classificados em: glicolipídeos, lipossacarídeos, lipopeptídeos, fosfolipídeos e ácidos graxos/lipídeo neutro, além de surfactantes poliméricos e surfactantes articulados, sendo os lipopeptídeos os biossurfactantes mais efetivos (Barros et al., 2007).

Os surfactantes lipoprotéicos são talvez os mais conhecidos por suas atividades antibióticas, sendo mais bem caracterizados aqueles produzidos por Bacillus $s p$, incluindo surfactina, iturina, fengicina, liquenisina, micosubtilisina e bacilomicina (Barros et al., 2007). A surfactina é reconhecida como um dos biossurfactante mais eficaz disponíveis, mas o alto custo e o baixo rendimento envolvidos na produção limitaram suas aplicações. Desta forma, o desenvolvimento de estratégias de alto rendimento e baixo custo de produção da surfactina é de demanda urgente (Yeh et al., 2006).

Atualmente, os biossurfactantes ainda não são capazes de competir economicamente no mercado com os compostos sintetizados quimicamente, devido aos altos custos de produção. Isso é resultado da metodologia ineficiente do bioprocessamento, da baixa produtividade das cepas microbianas e da necessidade do uso de substratos de custo elevado. (Haba et al ., 2000). Estima-se que os substratos representem de 10 a $30 \%$ do custo total da maioria dos processos biotecnológicos (Muthusamy et al., 2008).

Desta forma, a utilização de substratos de baixo valor econômico é uma forma de se reduzir o custo final de produção de metabólitos microbianos. Uma alternativa que vem sendo pesquisada extensivamente nos últimos anos é a utilização de resíduos agroindustriais como substratos para a produção de diversos compostos de origem microbiana, como os biossurfactantes. Resíduos ricos em carboidratos ou lipídeos, com adequada relação carbono/nitrogênio e que apresentem altas concentrações de micronutrientes importantes para o metabolismo microbiano são os que se caracterizam como melhores substratos para o crescimento microbiano, como também para a produção de biossurfactantes (Barros et al., 2008).

Vários são os fatores que afetam a produção dos biossurfactantes, como natureza das fontes de carbono e nitrogênio utilizadas, assim como a presença de fósforo, ferro, manganês e magnésio no meio de produção. Além disso, outros fatores, como $\mathrm{pH}$, 
temperatura, agitação e forma de condução do processo são extremamente importantes na quantidade e na qualidade do biossurfactante produzido (Banat, 1995).

Sendo assim, o presente trabalho teve como objetivo a produção de biossurfactante, mais precisamente a surfactina, através da fermentação do resíduo do processamento do abacaxi, por Bacillus subtilis, a $37{ }^{\circ} \mathrm{C}$. A aplicação do resíduo do abacaxi como substrato de fonte renovável garante o baixo custo na produção do surfactante microbiológico, uma vez que este fruto é extensivamente cultivado no Brasil, o qual é o segundo maior produtor mundial.

\section{MATERIAIS E MÉTODOS}

\subsection{Materiais}

Microrganismo: A bactéria Bacillus subtilis ATCC 6051 Lote T17/01/I pertence à Coleção de Culturas Tropical e foi gentilmente cedida pela Fundação André Tosello.

Substrato: para a produção do biossurfactante foi utilizado como substrato resíduo do processamento do abacaxi gentilmente cedido pelo hortifrúti Oba de Campinas-SP.

Meio de Cultura: para o crescimento do microrganismo foi utilizado o meio de cultura ágar nutriente, $\mathrm{pH} 7.4 \pm 0.2$, fabricante OXOID [ $\left[\mathrm{g} . \mathrm{L}^{-1}\right)$ extrato de carne $1,0 \mathrm{~g}$; extrato de levedura 2,0g; peptona 5,0g; cloreto de sódio 5,0g; ágar 15,0g].

Tampão $\mathrm{pH}$ 8,0: para manter o $\mathrm{pH}$ do substrato constante durante a fermentação, foi preparada solução tampão fosfato $\mathrm{pH} 8,0$, seguindo a metodologia descrita por Morita e Assumpção (1995).

\subsection{Métodos}

\section{Condições de cultivo e produção do biossurfactante}

Repique do microrganismo: foram realizados 10 tubos de repique do Bacillus subtilis. Os tubos contendo ágar nutriente foram autoclavados por 15 minutos e deixados em repouso até esfriar. O repique foi então realizado, com auxílio de alça de platina e bico de bulsen. Os tubos repicados foram incubados por 24 horas e mantidos refrigerados.

Preparação do pré-inóculo: foi preparada uma solução de peptona a $2 \%$ em água destilada em erlenmeyer de $250 \mathrm{~mL}$. Essa solução foi autoclavada por 15 minutos e, após resfriada, inoculou-se a cultura com auxílio de alça de platina e bico de bulsen. Posteriormente, foi mantida em banho a $30^{\circ} \mathrm{C}$ com agitação a $120 \mathrm{rpm}$ por 24 horas.

Meio de produção: em seis frascos de $250 \mathrm{~mL}$ foram adicionados $60 \mathrm{~mL}$ de caldo do abacaxi previamente filtrado e $20 \mathrm{~mL}$ de tampão $\mathrm{pH} 8,0$. Os frascos foram esterilizados em autoclave à $121^{\circ} \mathrm{C}$, por 10 minutos

Produção do biossurfactante: as fermentações para a produção foram realizadas com seis erlenmeyers de $250 \mathrm{~mL}$, contendo o meio de produção anteriormente descrito e em cada um deles acrescidos $16 \mathrm{~mL}$ do pré-inoculo (20\%). Foram mantidos sob agitação 
de $120 \mathrm{rpm}$, à $37^{\circ} \mathrm{C}$, por 52 horas. As amostras foram submetidas à determinação de tensão superficial e índice de emulsificação.

Tensão superficial: a medida da tensão superficial foi realizada de acordo com o método do peso da gota descrito por Behring (2004).

Índice de emulsificação: a emulsificação foi medida através da proporção óleo/biossurfactante, de acordo com a metodologia proposta por Cooper e Goldenberg (1987). Foram utilizados 3 diferentes tipos de óleos (óleo de soja, diesel e óleo de motor) e a análises feitas em duplicatas.

\section{RESULTADOS E DISCUSSÃO}

Por não haver registros bibliográficos da produção de biossurfactantes utilizando resíduo do processamento do abacaxi como substrato, fez-se um teste prévio realizando a fermentação em 6 frascos contendo apenas o caldo do abacaxi, à $37^{\circ} \mathrm{C}$, com agitação de 120rpm, por 72 horas e realizando o teste de tensão superficial. Nesse processo prévio de produção obteve-se redução de $20 \%$ da tensão superficial, comprovando então a possibilidade de se produzir biossurfactantes a partir de resíduo do abacaxi.

Posteriormente, a fermentação foi feita nas seguintes condições: $37^{\circ} \mathrm{C}, 120 \mathrm{rpm}$, pH 8,0 e $20 \%$ de inoculo. Para esta segunda fermentação foi analisada a tensão superficial e o índice de emulsificação.

\subsection{Tensão Superficial}

A tensão superficial, determinada através do método do peso da gota, apresentou resultados bastante favoráveis no que diz respeito à produção de biossurfactantes. A diminuição da tensão superficial ao longo do tempo de fermentação indica o aumento da produção de biossurfactantes por Bacillus subtilis em caldo de abacaxi. Tal decréscimo da tensão, nas condições impostas para esta fermentação, manteve-se constante após 27 horas de fermentação, como pode ser observado no gráfico abaixo:

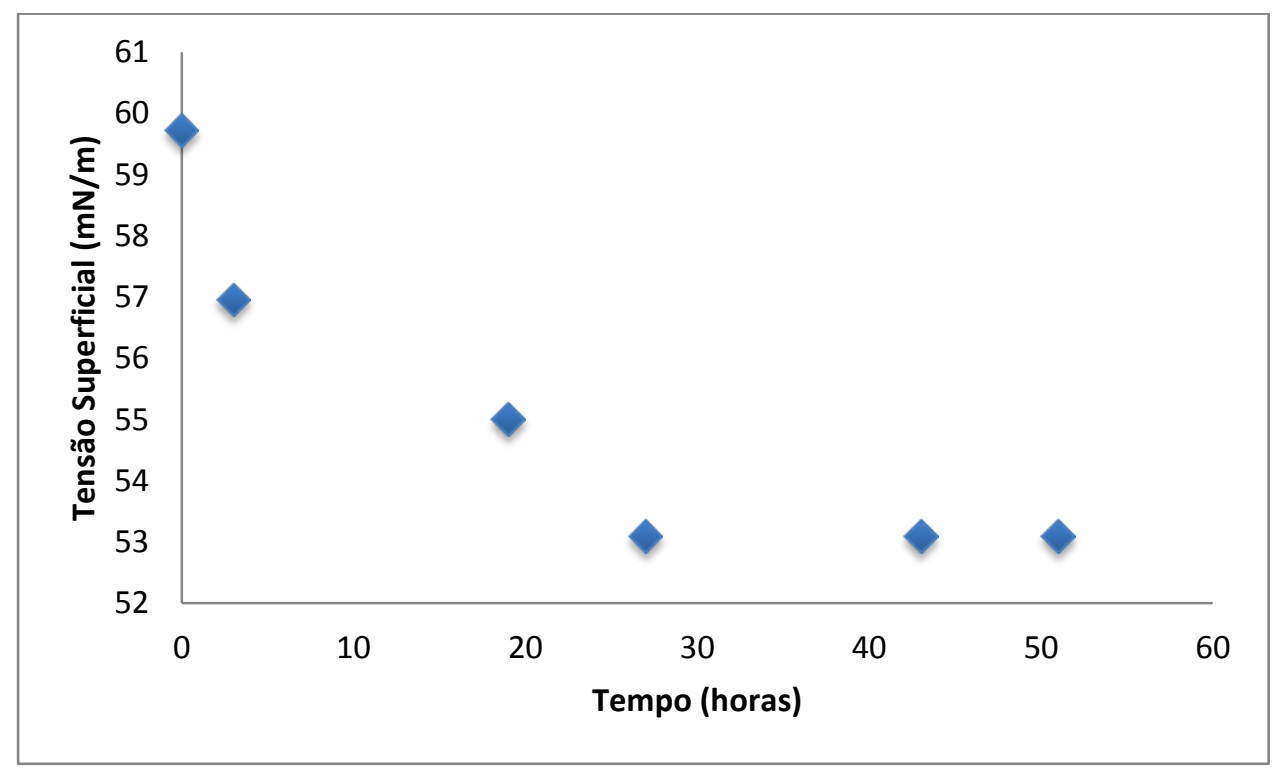

Figura 1 - Análise da tensão superficial ao longo do tempo. 
O estudo de produção de biossurfactantes utilizando o resíduo do processamento do abacaxi como substrato é bastante promissor, havendo a necessidade de ensaios em outras condições para se chegar a uma condição ótima, na qual haja maior redução da tensão superficial, ou seja, maior produção de biossurfactante no período de tempo determinado.

\section{2. Índice de Emulsificação}

Para análise do índice de emulsificação, foi adicionado à $1 \mathrm{~mL}$ de óleo, $1 \mathrm{~mL}$ do líquido metabólico livre de células em tubos graduados e agitados em vórtex por 1 minuto.

Após 24 horas, o cálculo de índice de emulsificação foi realizado seguindo a Equação 1, descrita a seguir:

$$
\%=\frac{\text { altura da emulsão } \times 100}{\text { altura total }}
$$

Foram testados óleo de soja, óleo diesel e óleo de motor. Os testes realizados com óleo diesel não apresentaram emulsão. A tabela 1 apresenta as porcentagens de emulsão quando feitos com óleo de soja e de motor.

Tabela 1: Índice de Emulsificação de acordo com a proporção óleo/biossurfactante.

\begin{tabular}{cccc}
\hline Amostra & Tempo (horas) & Óleo de Soja & Óleo de Motor \\
\hline $\mathbf{1}$ & 3 & $50.0 \%$ & $37.9 \%$ \\
$\mathbf{2}$ & 19 & $43.6 \%$ & $46.9 \%$ \\
$\mathbf{3}$ & 27 & $46.9 \%$ & $53.6 \%$ \\
$\mathbf{4}$ & 43 & $53.1 \%$ & $53.6 \%$ \\
$\mathbf{5}$ & 51 & $46.9 \%$ & $45.2 \%$ \\
\hline
\end{tabular}

\section{CONCLUSÃO}

A produção de biossurfactantes por Bacillus subtilis utilizando como substrato o resíduo do processamento do abacaxi se mostrou bastante efetiva uma vez que se obteve $20 \%$ de redução da tensão superficial e uma atividade emulsificante de $53 \%$. As diversas vantagens apresentadas pelos biossurfactantes quando comparados aos surfactantes sintéticos permitem o uso em diferentes ramos industriais. O problema econômico gerado pelo alto custo da produção de biossurfactantes pode ser minimizado a partir do uso de fontes renováveis como substrato e tal processo pode ser melhorado e ampliado com o desenvolvimento de novas tecnologias de aplicação e adequação nas condições de produção. 


\section{REFERÊNCIAS}

BANAT, I.M. Biosurfactants Production and Possible Uses in Microbial-Enhanced Oil Recovery and Oil Pollution Remediation: A Review. Bioresour. Technol., v.51, p. 1-12, 1995.

BARROS, F.F.C.; QUADROS, C.P.; MÓSTICA JÚNIOR, M.R.; PASTORE, G.M. Surfactina: Propriedades Químicas, Tecnológicas e Funcionais para Aplicações em Alimentos. Quim. Nova, 30(2): 409-14, 2007.

BARROS, F.; PONEZI, A.; PASTORE, G. Production of biosurfactant by Bacillus subtilis LB5a on a pilot scale using cassava wastewater as substrate. J. Ind. Microbiol. Biotechnol., v. 35, n. 9, p. 1071-1078, 2008.

BEHRING, J.L.; LUCAS, M.; MACHADO, C.; BARCELlOS, I.O. Adaptação no Método do Peso da Gota Para Determinação da Tensão Superficial: Um método simplificado para a quantificação da CMC de surfactantes no Ensino da Química. Quim. Nova, 27(3): 492-5, 2004.

BRADFORD, M. M. A Rapid and Sensitive Method for a Quatitation of Microgram Quantities of Proteins Utilizing the Principle of Protein-Dye Binding. Anal. Biochem., v. 72, p.248-254, 1976.

COOPER, D.G.;GOLDENBERG, B.G. Surface-active agents from two Bacillus s pecie. Appl. Env. Microbiol. v. 53, p. 224-229, 1987.

GHOJAVAND, H.; VAHABZADEH, F.; ROAYAEI, E.; SHAHRAKI, A.K. Production and properties of a biosurfactant obtained from a member of the Bacillus subtilis group (PTCC 1696). J Colloid Interface Sci., v. 324(1-2): 172-6, 2008.

HABA, E.; ESPUNY, M.J.; BUSQUETS, M.; MANRESA, A. Screening and production of rhamnolipids by Pseudonomas aeruginosa 47T2 NCIB 40044 from waste frying oils. J. Appl. Microbiol., v. 88, p. 379-387, 2000.

MORITA, T.; ASSUMPÇÃO, R. M. V. Manual de soluções, reagentes e solventes. Padronização, preparação, purificação. São Paulo: Editora Edgard Blücher Ltda, 1995.

MUTHUSAMY, K.; GOPALAKRISHNAN, S.; RAVI, T. K.; SIVACHIDAMBARAM, P. Biosurfactants: Properties, comercial production and application. Current Science, v. 94, n. 6, p. 736-747, 2008.

NITSCHKE, M.; PASTORE, G.M. Production and properties of a surfactant obtained from Bacillus subtilis grown on cassava wastewater. Bioresour. Technol., 97(2), 336-41, 2006.

YEH, M.S.; WEI, Y.H.; CHANG, J.S. Bioreactor design for enhanced carrierassisted surfactin production with Bacillus subtilis. Process Biochem.,41(8):1799-805, 2006. 